ISSN No. 0974-035X

An indexed refereed \& peer-reviewed journal of higher education

Towards Excellence

UGC-HUMAN RESOURCE DEVELOPMENT CENTRE

Gujarat University, Ahmedabad-380009, Gujarat, India

\title{
A REPRESENTATIVE REVIEW OF FUZZY LOGIC APPLICATIONS IN TOURISM RESEARCH
}

\author{
Dr. J. Eugene
}

\begin{abstract}
Tourism offers many tangible benefits to society with the industry playing an important contributory role in the growth and development of the domestic economy. The quantum of research studies on tourism has increased substantially over the last twenty years in tandem with the upward trajectory of the global tourist industry. The many different dimensions and aspects of tourism have been explored by a wide and varied spectrum of research studies. As the entire world came to a standstill with the Covid-19 pandemic induced global lockdown, tourism research witnessed a steady growth in research publications although the industry itself as well as the intertwined hotel and hospitality sector were crippled by a miniscule virus and left battling for their very survival. This increased quantum of literary publication was particularly evident in Scopus and Web of Science which put forth several notable publications on the changing dynamics of the tourism industry. The present study is envisaged to offer a holistic view of the future growth trends of the tourism industry, which has been forced to rethink the very fabric of its functioning and reinvent itself to adapt to a changed environment that curbs the social interaction that the industry depends on to function. Fuzzy logic, a mathematical modelling that can predict outcomes based on inputted data, has gained a lot of attention in recent years as it is an effective tool that can be deployed to envisage a course of action for future scenarios and devise feasible solutions that can help tackle uncertain and ambiguous situations. The current research paper, comprehensively reviews highly cited noteworthy articles on fuzzy logic and its application in tourism, to offer a good understanding of the applications and advantages of this dynamic modelling tool whose use in a number of different fields may soon make it indispensable to research and development. This qualitative paper is constructed on the basis of content analysis of numerous important articles that were reviewed in-depth. Based on the observations and findings of the study, research directions for the future are proffered. This paper is novel in that it focuses on one particular segment of research, i.e. new computing methods based on fuzzy logic, and can greatly help upcoming
\end{abstract}


researchers to explore the large number of real-life applications of this extremely useful tool and add meaningful knowledge to the existing literature with further research in the field of fuzzy logic models.

Keywords: Fuzzy logic, Fuzzy themes, Future, Pandemic, Research trends, Tourism Research

\section{Informative Introduction}

A vital success component of any industry is how well its research infrastructure scaffolds growth and fosters development. The industry as an entity makes continuous strides to develop new applications, innovative products, improved services, etc., all of which are quite critical in offering a better understanding of an ever-changing and constantly evolving customer-centric industry such as tourism. The complete network encompassing different services and service providers in the tourism sector relies on the recommendations of its investigative research body which seeks continual widening of the customer base and improvement of service quality. So far, several sound recommendations backed by substantial research have been implemented in tourism management across the world based on reliable research outcomes. The unprecedented current pandemic situation and the consequent slowdown of the economy have led to a greater reliance on the expertise of researchers who have redoubled/focussed their efforts to address the needs and requirements unique to the tourism industry which is eager to move forward and is gearing up to formulate strategies addressing the challenge of restoring normalcy. This is gaining increasing importance in the light of the unexpected virus onslaught from which the entire world is emerging only to face new post-pandemic challenges. The future of tourism remains largely uncertain to date in the aftermath of the pandemic but the industry has showed resilience by quickly adapting to the enforced stay-at-home scenario by offering armchair travellers carefully curated online travel experiences through virtual tours. The focus of the industry will now be on devising effective strategies to boost the tourism industry which is rapidly gaining momentum and well on its way to reach greater heights. The sector must redouble its efforts to build future resilience whilst doing all it can to address the health and safety concerns to allay the fears of travellers. The academic perspectives of researchers have helped in understanding the impact and implications of the slowdown of the tourism industry. They have accelerated progress in tourism by identifying knowledge gaps and systematically addressing research problems thereby fuelling the growth of the industry. An initial screening of various research studies and publications shows, that tourism research has focused more attention on technologies such 
as artificial intelligence, digital applications, tourism demand, tourism policy, tourism economics, destination management, tourists' perceptions, sustainable tourism, medical tourism, tourism innovation, heritage and cultural tourism and so on in the recent past. Though all these areas are vital contributors to our nation's progress, several advancements can also be witnessed in the field of fuzzy logic and its application in tourism. The popularity of this mathematical model can be attributed to its application to any area of tourism research. Hence, to gain a better understanding of fuzzy logic, some related articles are analysed in the current study.

\section{Obtainable Objectives}

Fuzzy logic approach is a mathematical modelling tool that analyses, manipulates, interprets and utilizes available data and information in order to manage complex and dynamic real-world situations; it is deployed to solve a number of problems of the tourism industry. It is a handy assessment and evaluation tool on the basis of which improvement measures are suggested for the many challenges associated with tourism. Since fuzzy-based applications in tourism are vast and wide, they cannot be covered in entirety by a single study. However, given the fact that the study is representative, the aims and objectives of this study have been narrowed down to:

- Identifying the areas of tourism research where fuzzy logic and fuzzy models have been used.

- Project areas in the tourism sector where functioning can be improved with application of fuzzy logic.

- Discuss possible solutions and expected outcomes with the implementation of fuzzy logic.

\section{Study Methodology}

The clarity of details presented in any research paper lies in the methodology utilized in structuring the contents. This study is carried out by a method called 'content analysis', a tool which is an important part of Qualitative research as it aids in arriving at reliable conclusions from the gathered data. The 'immersion' technique is the analytical style that is adopted for the content analysis where the researcher is deeply involved with the gathered data. . Scopus database and the Web of Science database are used to search and locate the required articles. The keywords used to identify the needed articles are, fuzzy logic in tourism, fuzzy in 
tourism, fuzzy applications in tourism, neural networks in tourism, fuzzy sets, and so on. Though scores of articles emerged from the search, 16 relevant articles alone are identified for review based on the citation metrics of the paper. There are two types of reviews while constructing a review paper. The most preferred method is the systematic review which includes a thorough review of a number of relevant articles before finally projecting the net outcome. The other alternative is a representative review where only a few selective articles are assessed with the assumption that they represent the whole entity. The present study opts for the representative review method and proffers an overview of the important role that fuzzy logic algorithms play in the tourism sector. Based on the judicious review of relevant resources, themes that emerge are grouped as these will give more impetus to future research.

\section{Appraisal and Analysis of Articles}

The focus of the study is on reviewing and analysing the contents of the 16 research articles identified for obtaining a better understanding of fuzzy logic and deeper insights into its applications. Researchers George, Ioanna, and Constantin (2018) used fuzzy logic to predict the success of a recently commenced service in the tourism sector. A hybrid intelligence system referred to as an Adaptive Neuro-Fuzzy Inference System (ANFIS) was used to boost the reasoning and learning capacity of the existing fuzzy logic. The researchers found that the application provided a far more accurate prediction than the other available forecasting models.

One of the key areas in tourism is the decision-making process of tourists who are desirous of locating an ideal destination, noteworthy tourist attractions that would most appeal to them and tourist locales that would be worth visiting. Fuzzy Tahani model calculates and offers suggestions of a careful selection as a supportive service to assist tourists in choosing the right tourist attraction. It employs various variables like the costs of the tickets, the available amenities, the number of tourists, distance travelled, and types of tourist attractions. This method has been proved to be the best in decision-making and in increasing tourism revenue (Wiwien, Edy, Arif and Dahlan, 2019)

Cluster-mapping is another interesting aspect of tourism. This is done to identify the most active geographic territory that has a robust economy offering varied activities, and tourism and travel-related services like hotels, restaurants, inns, car rental services, guided tour operators, travel agencies and so on. Fuzzy clustering methods are enabled and coupled with a Global positioning system (GPS) to calculate the neighbouring territories and their distance from the other territories. This method has been proved to be accurate in calculating the 
distance between two tourism clusters and aids in exactly projecting their economic activities (Justyna and Szymon, 2018).

The adverse environmental impact of tourism on natural habitats due to excessive recreational activities is an ongoing topic of research as it is synonymous with climate change and global warming. Guidelines for promoting responsible tourism development and good management practices are particularly of importance in mass tourism and niche tourist spots. A proper balance between the economic, environmental and sociocultural aspects of tourism development must be ensured within the context of sustainability for its long term growth. Many researchers have attempted to understand and evaluate the connection between tourism and the environment through a mechanism called Environmental Impact Assessment (EIA). Picture Fuzzy PROMETHEE II method is employed here to understand the ranks that emerge through assessment and decisions concerning environmental assessment. This model is proven to be more accurate than the previous models (Chao, Juan-juan, Wen-yu, Shuai, et al, 2020).

As tourism is considered an important contributor to the economy, governments of all countries focus attention on the development of policies and implementation of innovative strategies to foster tourism growth and frame sustainable tourism development policy objectives. Tourism governance, tourism development guidelines, management practices and policy effectiveness can all be enhanced by a supportive government network which is vital in determining the success of tourism in a particular State or district. To explore the contributory role of the government in strengthening the position of tourism, a fuzzy set qualitative comparative analysis (fsQCA) was used to compare a few networks of Sardinian tourism. The end result revealed that the networks had inter-dependent determinants that proved to be very effective in public management and administration with regard to tourism in Italy (Nicoletta and Federico, 2020).

Hotels and the hospitality sector are an integral part of tourism that cater to the comfortable stay of tourists. Predicting the arrival of tourists using reliable occupancy forecasting tools helps hotels to plan accommodation arrangements based on future hotel traffic estimates and maximize occupancy rates depending on demand. Such planning helps in the smooth, efficient and profitable functioning of the hotel industry. A fuzzy-rule based simulation was structured to make a reliable forecast of tourist footfall to a Hotel with the help of occupancy time-series data gathered over a time period of 40 months and by devising a fuzzy c-means clustering algorithm. This method proved to be the most accurate model for forecasting hotel occupancy (Rashad, Sara, and Rafig, 2019). 
The accurate prediction of tourist arrival and forecast of future tourism demand is undertaken in several ways. In recent years, many models have been tested to forecast the probable inbound tourism to provide information necessary for planning of tourism products and services. Fuzzy-based predictions have taken center stage for the important role they play in such forecasting. A novel model called the fuzzified grey prediction model that used neural networks was found to be appropriate as it eliminated uncertainties (Yi-Chung and Peng, 2020).

Innovative methods are needed to identify emerging tourism trends in any locale. In an endeavour to achieve greater accuracy in forecasting tourism demand, the fuzzy time series (FTS) was combined with Atom search optimization (ASO) algorithm, which proved to be particularly suited for small sample sizes (Ping, Hufang, Ranran and Chen, 2020).

One of the key concerns of the tourism industry in recent times has been gearing up to face the challenge of the unprecedented pandemic that has curtailed its smooth functioning. Modern approaches are the need of the hour to identify the specific economic challenges and emerging/key issues of the tourism industry for developing strategies to address the global problem of rebounding from the aftermath of the lockdown. Fuzzy logic has played a major role in effectively modelling the relaxation of protocols in the wake of Covid-19. An intuitionistic fuzzy DEMATEL analysis model was used and the findings offered practical ways to facilitate lockdown relaxations and mitigate the socio-economic impacts of the pandemic on a country (Lanndon and Kafferine, 2020).

Tourists today have a greater awareness of the repercussions of mass tourism and actively avoid visiting overcrowded destinations and vacationing during particular holiday seasons when tourism activities are much in demand and tend to peak. Cognition of the detrimental effects of uncontrolled tourism has resulted in tourists paying special attention to alternative tourism options, taking into account the environmental implications of their vacation decisions and selecting tourism destinations that have low-carbon footprints. This area has been very successfully explored with the help of fuzzy logic. Pythagorean fuzzy taxonomy method is used to effectively eliminate uncertain information while dealing with multiple attribute group decision-making (MAGDM) issues. This helps in the selection of a right vacation destination that not only meets the specifications of the tourists but also has the advantage of low-carbon imprints (Guiwu, Yanxin, Mengwei, Rui et al. 2020).

The recommendations of optimal tourism destinations based on several conditions and criteria were studied using an integrated picture fuzzy ANP-TODIM Multi-criteria decisionmaking approach. This approach eliminated the uncertainties that existed in the previously 
discussed version of choosing a tourism site and was found to be the best model for suggesting a low-carbon footprint tourism attraction (Chao and Juan-juan, 2020).

Intelligent data analysis with application of fuzzy logic can help in gaining information about the safety factor of a tourist destination with a history of terrorism. The risk perceptions of tourism locales under threat of random terrorist attacks, the dangers of an unsafe destination and fear of an imminent attack may be intimidating to tourists who prioritise safety and will hence affect their destination choice and travel decision. This fact was explored in a study which assessed various tourist risk evaluation criteria using the Fuzzy-VIKOR method where opinions of tourists were ranked and alternatives determined. Decision-making was consequently more reliable in this case (Yousaf, Zainab, and Amin, 2018).

The holistic development of tourism in a country primarily rests in the hands of the host community, i.e. the residents. Their perception of the effects of tourism on their community largely depends on the economic, socio-cultural, and environmental impacts of tourism. With the recognition of the many tangible benefits of tourism and its importance in furthering prosperity, there is greater citizen involvement in fostering tourism development and better cooperation with governmental agencies in maintenance and improvement of public services. In this regard, a hybrid-fuzzy method was used to compute residents' perception of tourism development (RPTD). Determinants based on fuzzy logic formed the base for evaluating a destination (Juan, Pedro and Concepcio'n, 2019).

Sustainable tourism places particular emphasis on actively vigorously promoting tourism while also ensuring the protection of the natural habitat and the preservation of the fragile ecosystem. The support to the local environment places importance on low-impact, responsible tourism and ensures that there is no exploitation of invaluable natural resources. Fuzzy logic systems are useful analytical tools that can help evaluate if sustainability targets are achieved based on diverse sets of indicators. Sustainability of ecotourism activities was programmed using a fuzzy linguistic prologue. It was used to effectively balance the activities of ecotourism with minimal impacts on the environment and without harming the natural habitat (Cakir and Ulukan, 2020).

Transport routes are an important part of planning a travel itinerary in tourism and route choice of travellers depends on various factors including existing road conditions. Tourists often choose the simplest, quickest and safest path to a specific tourist spot and ready availability of these details will be very helpful to them. In order to optimize transport routes and maximise travel efficiency, a weighted fuzzy graph coupled with the Flyod-Warshall 
Towards Excellence: An Indexed, Refereed \& Peer Reviewed Journal of Higher Education / Dr. J. Eugene / Page 324-336

algorithm was used, and it indicated that road width was one of the key factors of the study (Utti and Bongga, 2019).

\section{Cascading Research Themes}

Having discussed the application of fuzzy logic to different areas of research in the field of tourism, the paper now classifies the themes that reveal the core area of concentration.

Table 1. Trending research areas in Tourism based on Fuzzy logic

\begin{tabular}{|c|c|c|c|}
\hline S.No & Year & Area of Research & Fuzzy model \\
\hline 01 & 2018 & $\begin{array}{l}\text { Evaluation of a new tourism } \\
\text { service }\end{array}$ & $\begin{array}{l}\text { Adaptive Neuro Fuzzy } \text { Inference System } \\
\text { (ANFIS) }\end{array}$ \\
\hline 02 & 2018 & Cluster-mapping & Fuzzy-Clustering model \\
\hline 03 & 2018 & $\begin{array}{l}\text { Image recovery of a terrorism } \\
\text { affected destination }\end{array}$ & Fuzzy-VIKOR method \\
\hline 04 & 2019 & $\begin{array}{l}\text { Decision on choosing an optimal } \\
\text { tourist attraction }\end{array}$ & Fuzzy Tahani Model \\
\hline 05 & 2019 & Forecasting hotel occupancy & Fuzzy c-means clustering algorithm \\
\hline 06 & 2019 & $\begin{array}{l}\text { Residents' perception of tourism } \\
\text { development }\end{array}$ & Hybrid-fuzzy method \\
\hline 07 & 2019 & Fastest route to a tourist site & $\begin{array}{l}\text { Fuzzy Linguistic Prolog, Flyod-Warshall } \\
\text { Algorithm }\end{array}$ \\
\hline 08 & 2019 & $\begin{array}{lcc}\text { Tourists' } & \text { online } & \text { review } \\
\text { recommendation system } & \\
\end{array}$ & Fuzzy-based multi criteria algorithms \\
\hline 09 & 2020 & $\begin{array}{ll}\text { Environmental } & \text { Impact } \\
\text { Assessment } & \\
\end{array}$ & Picture Fuzzy PROMETHEE II method \\
\hline 10 & 2020 & $\begin{array}{l}\text { Performance of governance } \\
\text { networks }\end{array}$ & $\begin{array}{l}\text { Fuzzy set qualitative comparative analysis } \\
\text { (fsQCA) }\end{array}$ \\
\hline 11 & 2020 & Tourism Demand Forecasting & Fuzzified grey prediction model \\
\hline 12 & 2020 & Tourism Demand Forecasting & Fuzzy time series (FTS) \\
\hline 13 & 2020 & $\begin{array}{l}\text { Relaxation of Covid-19 lockdown } \\
\text { protocol }\end{array}$ & $\begin{array}{l}\text { Intuitionistic fuzzy DEMATEL analysis } \\
\text { model }\end{array}$ \\
\hline 14 & 2020 & $\begin{array}{l}\text { Choosing low-carbon tourism } \\
\text { destinations }\end{array}$ & Pythagorean fuzzy taxonomy method \\
\hline 15 & 2020 & $\begin{array}{lll}\begin{array}{l}\text { Choosing } \\
\text { destinations }\end{array} & \text { optimal } & \text { tourism } \\
\end{array}$ & $\begin{array}{l}\text { Integrated picture fuzzy ANP-TODIM Multi } \\
\text { criteria decision making approach }\end{array}$ \\
\hline 16 & 2020 & Ecotourism sustainability & Fuzzy linguistic prolog \\
\hline
\end{tabular}

On the basis of the above understanding, certain trends warranting future research can be observed, namely the forecasting of tourism demand and the optimal selection of tourism destinations. The remaining areas can be grouped into the two categories set out below: 


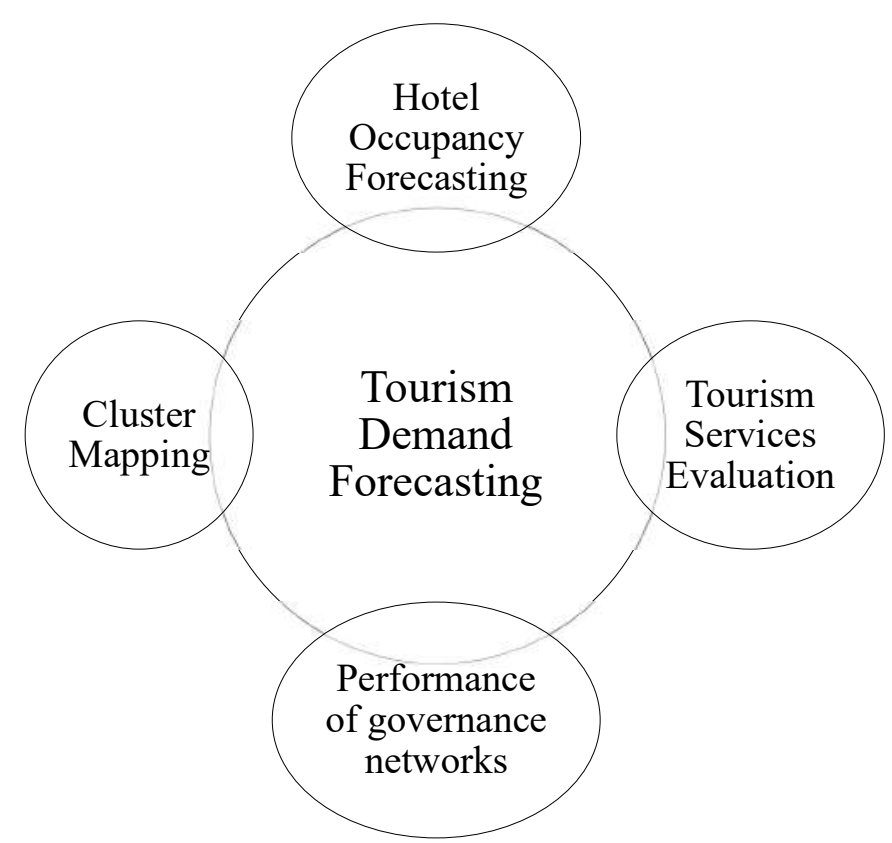

Fig 1. Grouped sub-themes for future research under 'Forecasting'

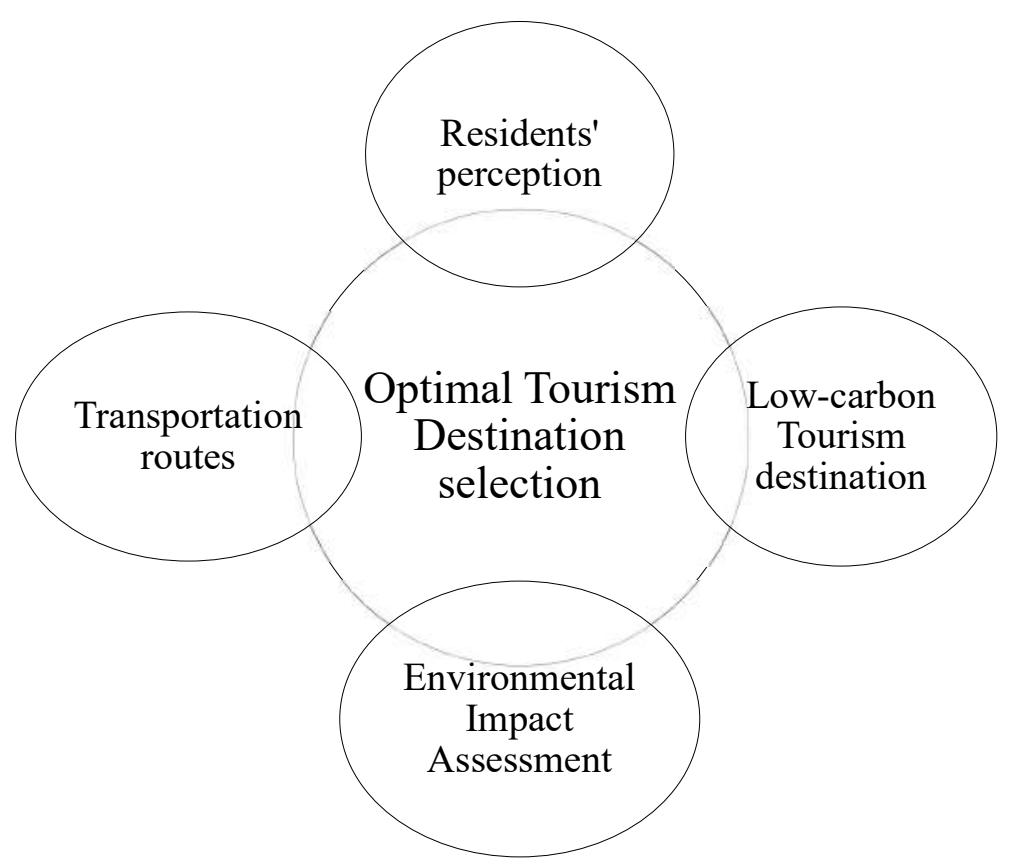

Fig 2. Grouped sub-themes for future research under 'destination selection' 


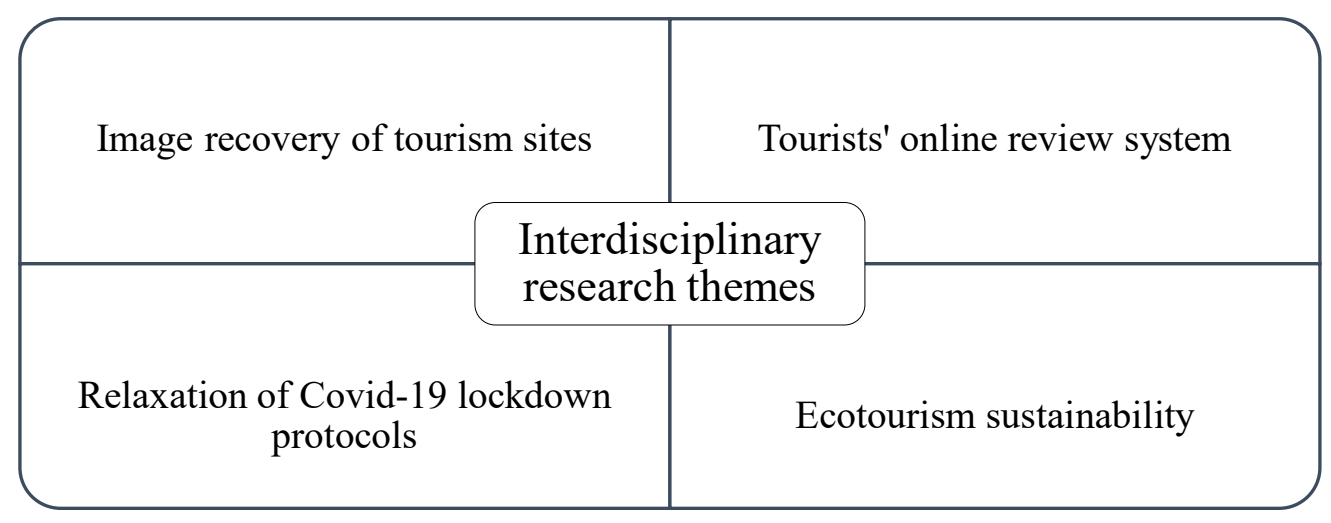

Fig 3. Sub-themes that can be collaborated with other themes of research

\section{Limitations of the study}

The present study is restricted to a representative view of the overall result, thereby limiting the size of the sample for content analysis. A systematic review generally includes a wide variety of insights into the work of different scholars and may include many other interesting themes. However, the purpose of this paper is only to provide an overview of a selected collection of research studies on fuzzy themes which offer insights into the application of fuzzy logic models in tourism.

\section{Epilogue}

The travel and tourism industry enjoys the reputation of being one of the largest growing service sectors in India. Devastated by the enforced stay-at-home and ban on mobility, the industry is now beginning to recover as lockdowns have been eased, it has been forced to adapt to the new-normal of the post-pandemic scenario. Shifting trends have been witnessed in travel patterns; there have been marked changes in tourists' behaviour and motivation to travel with preference for socially distanced tours and small group travel activities. Application of fuzzy logic-based techniques of forecasting methods have helped the industry to navigate the situation with the deployment of a mathematical tool that is capable of modelling uncertainty and organising data to support decision-making. This problem-solving modelling technique offers a number of fuzzy models that can help to reduce the complexity in improving and developing tourism services. 
The goal of this investigative research study was to review the most cited papers on fuzzy logic, understand its applications in tourism research and to discover important themes from the comprehensive content analysis. The paper has thoroughly reviewed the selected articles and succinctly summarised the important findings. The models used by fuzzy logic are also structured, making it easy for other researchers to understand their application and verify them in their own studies. From the study, it is evident that the focus of most researchers has been on showcasing the positive side of the post-pandemic scenario. It is evident that all the articles reviewed do not consider the pandemic as a cause for a pause in research activities with researchers accepting the reality of living with the pandemic and remaining optimistic about the future of tourism. An ambitious path forward has been envisaged for the tourism sector as it has been in the past and a range of newer research areas that could benefit from the use of predictive modelling with the application of fuzzy logic have been identified. This study is meaningful in that it not only highlights new research areas where fuzzy logic techniques could be effectively employed to support decision-making and planning but also specifically directs prospective researchers to investigate the target areas using a number of appropriate fuzzy models. 


\section{References}

Çakır, E., \& Ulukan, Z. (2020). A Fuzzy Linguistic Programming for Sustainable Ecotourism Activities, 10th Annual Computing and Communication Workshop and Conference (CCWC), Las Vegas, NV, USA, pp. 0121-0126, doi: 10.1109/CCWC47524.2020.9031187

Chao, T., Juan-juan, P. (2020). An Integrated Picture Fuzzy Anp-Todim Multi-Criteria Decision-Making approach for Tourism Attraction Recommendation, Technological and Economic Development of Economy, Volume 26 Issue 2: 331-354, https://doi.org /10.3846/t ede.2019.11412

Chao, T., Juan-juan, P., Wen-yu, Z., Shuai Z., \& Jian-qiang, W. (2020). Tourism environmental impact assessment based on improved AHP and picture fuzzy PROMETHEE II methods, Technological and Economic Development of Economy, 2020 Volume 26 Issue 2: 355-378, https://doi.org/10.3846/tede.2019.11413

George, S. A., Ioanna, G. A., \& Constantin, Z. (2018). Forecasting the success of a new tourism service by a neuro-fuzzy technique, European Journal of Operational Research, doi: 10.1016/j.ejor.2018.01.044

Guiwu, W., Yanxin, T., Mengwei, Z., Rui, L., \& Jiang, W. (2020). Selecting the Low-Carbon Tourism Destination: Based on Pythagorean Fuzzy Taxonomy Method, Mathematics, 8, 832; doi: $10.3390 /$ math 8050832

Justyna, M., \& Szymon, T. (2018). Cluster-mapping procedure for tourism regions based on geostatistics and fuzzy clustering: example of Polish districts, Current Issues in Tourism, doi: $10.1080 / 13683500.2018 .1467883$

Juan, C. M., Pedro, M., \& Concepcio'n, R. (2019). A hybrid-fuzzy segmentation analysis of residents' perception towards tourism in Gran Canaria, Tourism Economics, (xx), (x), https://doi.org/10.1177/1354816619873463

Nicoletta, F., \& Federico, R. (2020). What combinations of conditions lead to high performance of governance networks? A fuzzy set qualitative comparative analysis of 12 Sardinian tourist networks, International Public Management Journal, doi: https://www.tandfonline.Com/act Ion/showCitFormats? doi=10.1080/10967494. 2020.1755400

Ping, J., Hufang, Y., Ranran, L., \& Chen, L. (2020). Inbound tourism demand forecasting framework based on fuzzy time series and advanced optimization algorithm, Applied Soft Computing Journal, Vol. 92, https://doi.org/10.1016/j.asoc.2020.106320

Rashad, A., Sara, S \& Rafig, A. (2019). Development of Fuzzy Time Series Model for Hotel Occupancy Forecasting, Sustainability, 11, 793; doi: 10.3390/su11030793

Lanndon, O., Kafferine, Y. (2020). Modeling the lockdown relaxation protocols of the Philippine government in response to the COVID-19 pandemic: An intuitionistic fuzzy DEMATEL analysis, Socio-Economic Planning Sciences, https://doi.org/10.1016/ j.seps. 2020 .100911, In Press 
Utti, M. R., \& Bongga, A. (2019). Tourism Transportation's Optimum Route in Banyumas using The Weighted Fuzzy Graph, The 2nd International Conference on Science, Mathematics, Environment, and Education, AIP Conf. Proc. 2194, 020104-1-020104-12; https://doi.org/10. $1063 / 1.5139836$

Wiwien, Edy, W., Arif B. P., \& Dahlan, A. (2019). Implementation of Tahani Fuzzy Logic Method for Selection of Optimal Tourism Site, 1st International Conference of SNIKOM 2018, Indonesia, Journal of Physics: Conference Series 1361, 012051, doi:10.1088/1742-6596/1361 $/ 1 / 012051$

Yi-Chung, H., \& Peng, J. (2020). Fuzzified grey prediction models using neural networks for tourism demand forecasting, Computational and Applied Mathematics, 39:145, https://doi.org/10.1007/s40314-020-01188-6

Yousaf, A., Zainab, A. S., and Amin, U. K. (2018). Post-terrorism image recovery of tourist destination: a qualitative approach using Fuzzy-VIKOR, Journal of Tourism Analysis: Revista de Análisis Turístico, Vol. 25 No. 2, doi: 10.1108/JTA-05-2018-0016

\section{Dr. J. Eugene \\ Lecturer \\ Institute of Hotel Management Catering Technology and Applied Nutrition, C.I.T Campus, Taramani, Chennai \\ E Mail: ihm.eugene@gmail.com \\ Mobile: +91-9445236984 \\ ORCID iD: https://orcid.org/0000-0001-6206-7938}

